\title{
Silencing the roadblocks to effective triple-negative breast cancer treatments by siRNA nanoparticles
}

\author{
Jenny G Parvani1,2 and Mark W Jackson²
}

'Department of Biomedical Engineering, Case Western Reserve University, Cleveland, Ohio, USA

${ }^{2}$ Case Comprehensive Cancer Center, Case Western Reserve University, Cleveland, Ohio, USA

Correspondence should be addressed to M W Jackson Email mwj7@case.edu

\begin{abstract}
Over the past decade, RNA interference (RNAi) has been ubiquitously utilized to study biological function in vitro; however, limitations were associated with its utility in vivo. More recently, small interfering RNA (siRNA) nanoparticles with improved biocompatibility have gained prevalence as a potential therapeutic option for the treatment of various diseases. The adaptability of siRNA nanoparticles enables the delivery of virtually any siRNA, which is especially advantageous for therapeutic applications in heterogeneous diseases that lack unifying molecular features, such as triple-negative breast cancer (TNBC). TNBC is an aggressive subtype of breast cancer that is stratified by the lack of estrogen receptor/progesterone receptor expression and HER2 amplification. There are currently no FDA-approved targeted therapies for the treatment of TNBCs, making cytotoxic chemotherapy the only treatment option available to these patients. In this review, we outline the current status of siRNA nanoparticles in clinical trials for cancer treatment and discuss the promising preclinical approaches that have utilized siRNA nanoparticles for TNBC treatment. Next, we address TNBC subtypespecific therapeutic interventions and highlight where and how siRNA nanoparticles fit into these strategies. Lastly, we point out ongoing challenges in the field of siRNA nanoparticle research that, if addressed, would significantly improve the efficacy of siRNA nanoparticles as a therapeutic option for cancer treatment.
\end{abstract}

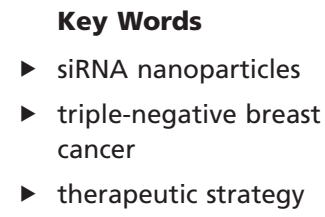

Endocrine-Related Cancer (2017) 24, R81-R97

\section{Introduction}

RNA interference (RNAi) is a process where small doublestranded RNAs consisting of approximately 22nt are utilized to repress gene expression. These effects were first observed in nematode worms in 1998, where expression of par-1 mRNA was temporarily depleted after the introduction of double-stranded small interfering RNA (siRNA) (Fakhr et al. 2016, Young et al. 2016). Further studies identified additional molecular players in the RNAi machinery, including Dicer and the RNA-induced silencing complex (RISC) (Kobayashi \& Tomari 2016).
Upon uptake of the double-stranded siRNA, Dicer unwinds and cleaves the sense strand (Fig. 1). The antisense strand then acts as a guide for the recognition of complementary mRNAs, and the RISC complex forms (Fig. 1). If the antisense strand is perfectly complement to the mRNA, the mRNA is cleaved by argonaute 2 (Ago2), the catalytic subunit of the RISC complex (Azlan et al. 2016, Fakhr et al. 2016). Limited complementarity to the target mRNA leads to translational repression, a function that is associated with micro RNAs (miRNAs) (Young et al. 2016). Since its

Published by Bioscientifica Ltd. 


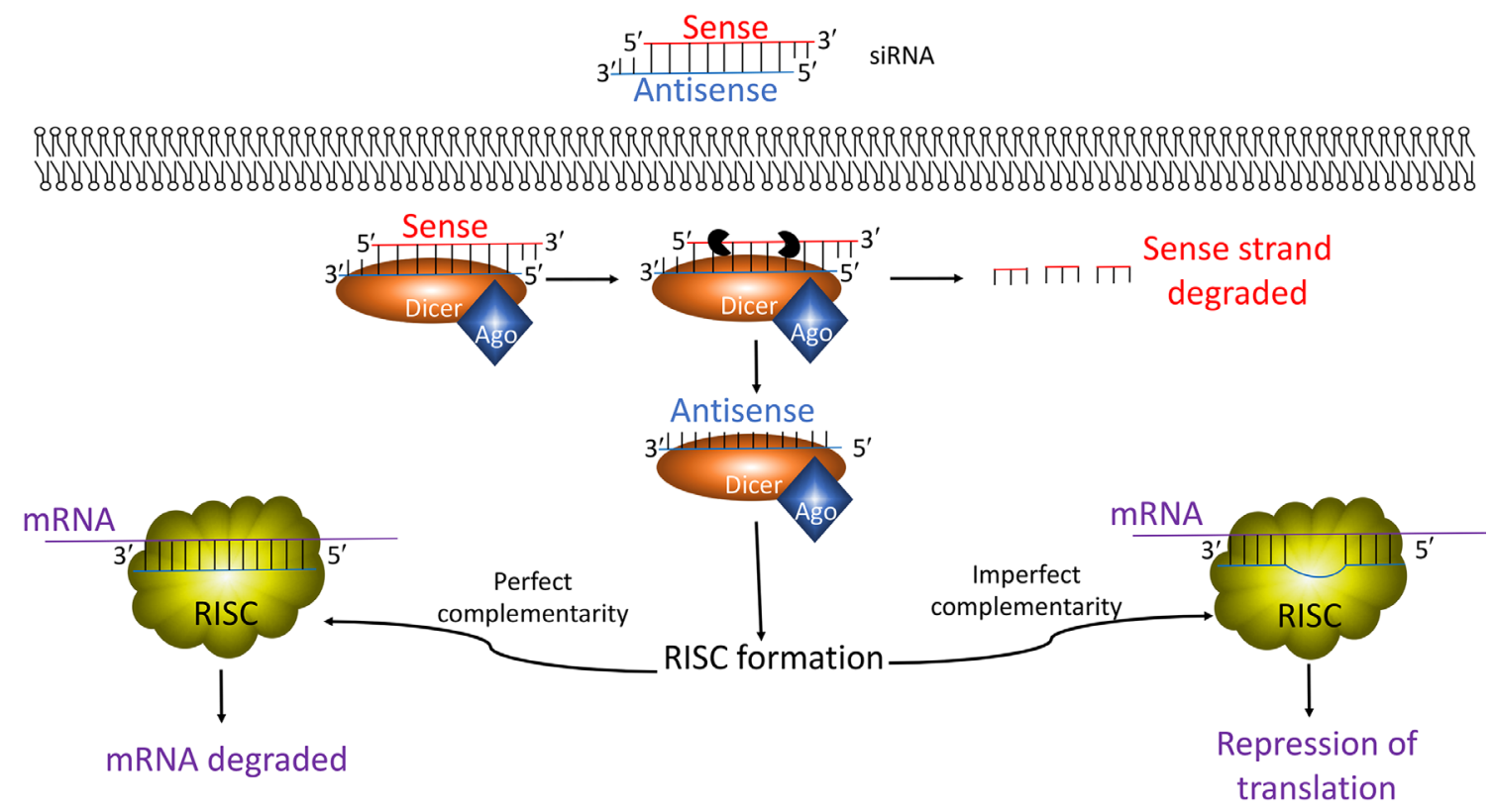

Figure 1

The siRNA machinery. Upon entry into the cell, the sense strand of the double-stranded siRNA is cleaved. The antisense siRNA strand then acts as a guide for mRNA complementation. Perfect complementarity between the antisense siRNA strand and the target mRNA leads to mRNA degradation, whereas imperfect complementarity between the two leads to the mRNA translational repression.

discovery, siRNAs have been widely utilized in vitro to interrogate various cell and molecular biology questions. However, siRNA use in vivo has been limited by its (1) labile nature, (2) anionic properties and (3) proclivity to raise immune responses. Therefore the use of siRNA in a therapeutic setting requires further shielding of the siRNA to address these challenges.

One method of overcoming these limitations is to encapsulate the naked siRNA within nanoparticles. Nanoparticles can be made from various materials (Wang et al. 2010, Jeong et al. 2011). Two main categories consist of organic and inorganic nanoparticles (Miele et al. 2012, Young et al. 2016). Organic nanoparticles are composed of materials that either occur naturally or from a synthesized source (Lopez-Davila et al. 2012, Young et al. 2016). These include but are not limited to (1) lipid nanoparticles such as micelles and liposomes and (2) polymer-based nanoparticles such as dendriplexes and cyclodextrin nanoparticles (Fig. 2) (Wen \& Steinmetz 2016, Young et al. 2016). Inorganic nanoparticles typically consist of non-biodegradable biomaterials including metals, metal oxides and other carbon materials (Young et al. 2016). Additional complex, hybrid nanoparticles that consist of both organic and inorganic biomaterials also exist. For readers desiring a more in depth understanding of nanoparticle biomaterials as well as advantages and disadvantages associated with each, we recommend several recent comprehensive reviews (Jeong et al. 2011, Miele et al. 2012, Young et al. 2016).

Nanoparticle size and surface charge significantly affect circulation time; therefore, a number of parameters and modifications are adapted to enhance nanoparticle longevity. Three major modes of nanoparticle clearance in vivo include urine excretion through the renal filtration system, biliary excretion through the liver filtration system and uptake by phagocytic cells of the immune system (Longmire et al. 2008, 2011). Importantly, nanoparticle accumulation and clearance by the kidneys, liver and blood are significantly dependent on the particle size and material (De Jong et al. 2008, Longmire et al. 2011). First, the glomerulus, or renal filtration functional unit, is capable of excreting nanoparticles with minimal catabolism of the particles. Particles that are excreted by glomerular filtration are typically $6 \mathrm{nM}$ or smaller in diameter (Longmire et al. 2008, 2011, Lorenzer et al. 2015). In addition to size, particle surface charge can also affect the efficiency of renal excretion. Previous studies demonstrate that among particles that are similar in size, positively charged particles are mostly effectively excreted, which is followed by neutral particles and lastly by negatively charged particles (Deen et al. 2001). These differences in charge-selective excretion is partly attributed to the negatively charged glomerular capillary wall that preferentially attracts positively charged particles 


\section{Lipid nanoparticles}

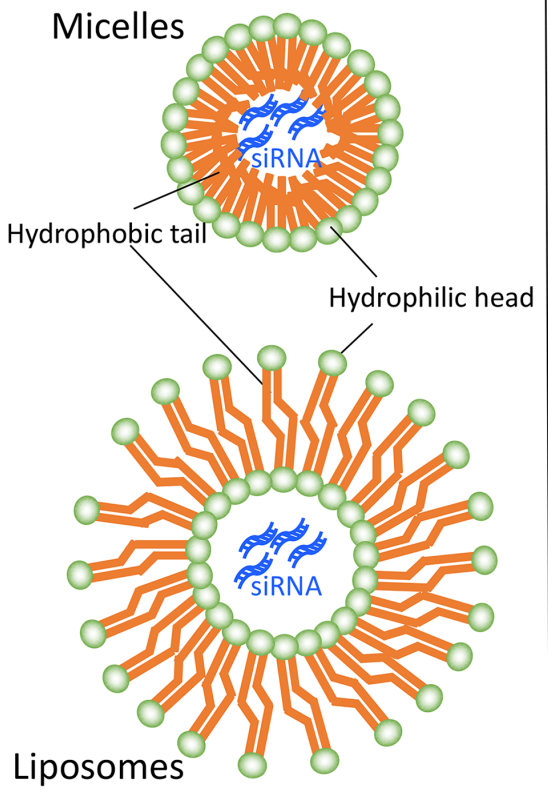

\section{Polymeric nanoparticles}

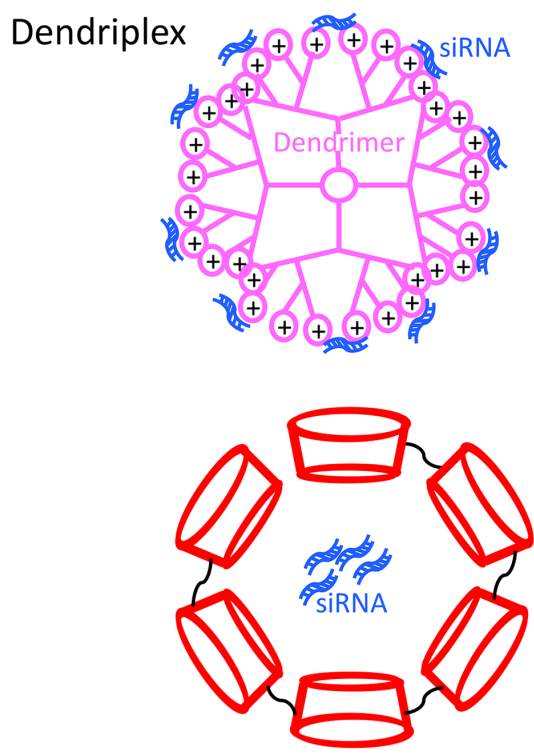

\section{Cyclodextrin}

\section{Figure 2}

Select examples of organic nanoparticles. Lipid nanoparticles include micelles and liposomes, which are composed of hydrophobic lipids that contain a hydrophilic head. Polymeric nanoparticles include dendriplexes and cyclodextrin nanoparticles. A dendrimer is a branched amphiphilic polymer and cyclodextrin is an amphiphilic cyclic oligosaccharide.
(Deen et al. 2001). Particles that escape renal excretion may be cleared by the liver. Within the liver, nanoparticles can be internalized by endothelial cells, hepatocytes and Kupffer cells, and different nanomaterials are selectively and differentially internalized by these cells (Heine et al. 2014, Bargheer et al. 2015). Hepatocyte and Kupffer cells further mediate the enzymatic breakdown of the engulfed particle, which range between 10 and $20 \mathrm{nM}$ in size (Longmire et al. 2008, 2011). Kupffer cells rely solely on intracellular breakdown of the engulfed material, whereas hepatocytes-mediated nanoparticle clearance also involves the excretion through bile (Longmire et al. 2008, 2011). Moreover, nanoparticles in circulation are also opsonized or tagged by serum proteins for phagocytosis by immune cells. Opsonization is affected by various nanoparticle characteristics such as hydrophobicity, size and charge (Alexis et al. 2008, Lim et al. 2008). Nanoparticles that are greater than $200 \mathrm{nM}$ are readily cleared by phagocytic immune cells (Lorenzer et al. 2015). In addition to size and charge, several additional factors also affect nanoparticle circulation time.

Surface modification with polyethylene glycol (PEG), a biocompatible polymer, has also been demonstrated to significantly increase circulation time by (1) reducing charge-based interactions with the glomerular capillaries and (2) shielding nanoparticles from phagocytic cells (Li \& Szoka 2007, Jokerst et al. 2011). The net effect of PEGylation is also associated with decreased cellular uptake of nanoparticles; therefore, additional modifications of the nanoparticles are required to improve accumulation within tumor cell. PEGylated nanoparticles are coated with a number of targeting ligands whose receptors are highly expressed on tumor cells to promote receptormediated endocytosis. Commonly utilized targeting ligands are summarized in Table 1 (Nahta \& Esteva 2006, Cao et al. 2011, Deng et al. 2013, Seitz et al. 2013, Feng et al. 2014, Necela et al. 2015, Parvani et al. 2015, Arosio \& Casagrande 2016, Bakrania et al. 2016, Gu et al. 2016, $\mathrm{Xu}$ et al. 2016). Importantly, these strategies significantly improve nanoparticle uptake by tumor cells. Various other factors including nanoparticle shape (Geng et al. 2007, Sadekar et al. 2011), flexibility (Kobayashi et al. 2001, Ogawa et al. 2010), surface coating (Heine et al. 2014, Bargheer et al. 2015) and cargo (Zintchenko et al. 2008, Scholz \& Wagner 2012) may all play a role in nanoparticle stability and life span.

There are several advantages to using siRNA nanoparticle platforms as a therapeutic strategy. Recent advances in next-generation high-throughput sequencing have revealed extraordinary genetic complexity and heterogeneity in cancer models (Hoelder et al. 2012). Because siRNAs are readily synthesized and can be optimized to maximize gene silencing (Fakhr et al. 2016), siRNA nanoparticles can be easily adapted to silence virtually any gene in mammalian cells. Various siRNA design software that enable the optimization of siRNA length, specificity and nucleotide content based on a number of criteria are available online

Published by Bioscientifica Ltd 
Table 1 Common strategies to improve nanoparticle accumulation in tumor cells.

\begin{tabular}{|c|c|c|}
\hline Targeting ligand & Receptor & References \\
\hline Vapreotide & Somatostatin receptor & $\begin{array}{l}\text { Feng et al. (2014) } \\
\text { Seitz et al. (2013) }\end{array}$ \\
\hline RGD & MMP2, integrins & $\begin{array}{l}\text { Parvani et al. (2015) } \\
\text { Arosio \& Casagrande (2016) }\end{array}$ \\
\hline Trastuzumab & HER2 & $\begin{array}{l}\text { Nahta \& Esteva (2006) } \\
\text { Gu et al. (2016) }\end{array}$ \\
\hline Folic acid & Folic acid receptor & $\begin{array}{l}\text { Necela et al. (2015) } \\
\text { Cao et al. (2011) }\end{array}$ \\
\hline Hyaluronic acid & HARE, LYVE1, RHAMM, CD44 & $\begin{array}{l}\text { Xu et al. (2016) } \\
\text { Bakrania et al. (2016) } \\
\text { Deng et al. (2013) }\end{array}$ \\
\hline
\end{tabular}

(Fakhr et al. 2016). These tools offer a quick way to focus screening of numerous siRNAs for numerous genes, which contrasts time-consuming traditional ways of searching for small molecule inhibitors against a target (Hoelder et al. 2012). siRNA nanoparticles are also equipped to silence splice variants and transcription factors, which were previously thought of as 'undruggable' (Johnston \& Carroll 2015). Not surprisingly, several siRNA nanoparticles are currently being tested in clinical trials as cancer therapeutics.

\section{Clinical application of siRNA nanoparticles in cancer treatment}

Preclinical studies in various different tumor models have demonstrated siRNA nanoparticles to be effective in inhibiting tumor growth (Parvani et al. 2015, Su et al. 2015, Zhang et al. 2016), metastasis (Parvani et al. 2015,
Zhao et al. 2015), angiogenesis (Liu et al. 2015, Malamas et al. 2016) and drug resistance (Deng et al. 2013, Zhang et al. 2016). These studies have paved the way for various ongoing clinical trials, which are summarized in Table 2. The efficacies of several different siRNA nanoparticles are currently being evaluated for safety and pharmacokinetics in phase 1 clinical trials, and among these, 4 studies have been completed and 1 has been terminated.

Atu027 is a lipid nanoparticle with a particle diameter of about $120 \mathrm{~nm}$ (Santel et al. 2006), delivering siRNA against protein kinase N3 (PKN3), a downstream effector of the PI3 kinase pathway, for the treatment of various solid tumors (Schultheis et al. 2014). In preclinical mouse models, silencing PKN3 is associated with decreased tumor growth and metastases (Aleku et al. 2008). The phase 1 clinical trial evaluating Atu027 consisted of 34 treatment-naïve patients harboring a variety of advanced

Table 2 siRNA nanoparticles being tested in clinical trials.

\begin{tabular}{|c|c|c|c|}
\hline $\begin{array}{l}\text { Clinical } \\
\text { trial phase }\end{array}$ & Drug name & $\begin{array}{l}\text { Nanoparticle } \\
\text { material }\end{array}$ & $\begin{array}{l}\text { Targeting } \\
\text { strategy }\end{array}$ \\
\hline 1 & Atu027 & Lipid nanoparticle & None \\
\hline I & ALN-VSP & Lipid nanoparticle & None \\
\hline I & TKM 80301 & Lipid nanoparticle & None \\
\hline I & CALAA-01 & $\begin{array}{l}\text { Polymer } \\
\text { (cyclodextrin) } \\
\text { nanoparticle }\end{array}$ & Transferrin \\
\hline I & siG12D LODER & $\begin{array}{c}\text { Polymer (PLGA) } \\
\text { nanoparticle }\end{array}$ & $\begin{array}{l}\text { Implanted } \\
\text { into tumor }\end{array}$ \\
\hline I & siRNA-EphA2-DOPC & Lipid nanoparticle & None \\
\hline II & siG12D LODER & $\begin{array}{l}\text { Polymer } \\
\text { nanoparticle }\end{array}$ & $\begin{array}{l}\text { Implanted } \\
\text { into tumor }\end{array}$ \\
\hline I & TKM 80301 & Lipid nanoparticle & None \\
\hline $\begin{array}{l}\text { http://erc.end } \\
\text { DOI: } 10.1530\end{array}$ & $\begin{array}{l}\text { docrinology-journals.org } \\
\text { /ERC-16-0482 }\end{array}$ & $\begin{array}{r}\text { (C) } 2017 \text { Society for } \\
\text { Printed }\end{array}$ & $\begin{array}{l}\text { Endocrinology } \\
\text { in Great Britain }\end{array}$ \\
\hline
\end{tabular}

\begin{tabular}{l} 
Target \\
\hline Protein \\
kinase N3 \\
VEGF and \\
KSP \\
Polo-like \\
kinase 1
\end{tabular}

cancer

Solid tumors

KRASG12D

EphA2

KRASG12D

Polo-like kinase 1 Solid tumors

\begin{tabular}{l} 
Disease \\
\hline Solid tumors \\
Solid tumors with \\
liver involvement \\
Primary or \\
secondary liver \\
cancer
\end{tabular}

Company

Silence

Therapeutics

Alnylam

$\mathrm{NCl}$

Calando

Terminated

Pancreatic ductal adenocarcinoma Solid tumors

Silenseed Ltd

$\mathrm{M}$

MD Anderson

Cancer Ctr

Pancreatic ductal adenocarcinoma

Silenseed Ltd.

Tekmira open

Not yet

open

\section{Stage} Completed

Completed

Completed

Recruiting 
solid tumors (Schultheis et al. 2014). These patients were intravenously infused with 10 escalating doses of Atu027, and results indicated that (1) these nanoparticles are well tolerated in patients up to $0.336 \mathrm{mg} / \mathrm{kg}$ and (2) $41 \%$ of patients exhibited stable disease for at least 8 weeks (Schultheis et al. 2014). These promising results have laid a solid foundation for additional clinical trials.

ALN-VSP is a lipid nanoparticle with a particle diameter of $80-100 \mathrm{~nm}$, delivering siRNA against vascular endothelial growth factor (VEGF) and kinesin spindle protein $(K S P)$ at a 1:1 molar ratio for the treatment of liver cancers (Tabernero et al. 2013). VEGF is a growth factor that is essential for angiogenesis, endothelial cell permeability and general preservation of vessel function (Gopal et al. 2016). KSP is a microtubule-interacting protein that is involved in the regulation of mitosis and apoptosis (Naymagon \& Abdul-Hay 2016). In a phase 1 clinical trial, patients received intravenous injections of ALN-VSP doses that ranged from 0.4 to $1.0 \mathrm{mg} / \mathrm{kg}$ (Tabernero et al. 2013). Tumor biopsies from 12 patients indicated significant accumulation of the siRNA and target mRNA cleavage within the tumor (Tabernero et al. 2013). Overall, ALN-VSP was well tolerated in patients and exhibited antitumor activity, including the complete regression of liver metastases originating from a primary endometrial tumor. Further development of ALN-VSP is expected.

TKM-080301 is a lipid nanoparticle-delivering siRNA against polo-like kinase1 (PLK1) (Liu 2015). PLK1 is a serine-threonine kinase that regulates mitosis, DNA replication and cellular stress response (Liu 2015). Elevated expression of PLK1 has been observed in various cancers, including but not limited to breast, colorectal, prostate and head and neck cancers (Takai et al. 2005). Preclinical studies have demonstrated that depletion of PLK1 expression preferentially inhibits the survival of tumor cells in xenograft models (Spankuch et al. 2004, Guan et al. 2005, Liu 2015). A phase 1 trial evaluating the pharmacodynamics of TKM-080301 in patients harboring lymphoma or advanced solid tumors has been completed; however, the trial report is currently unavailable.

CALAA-01 is a cyclodextrin-based polymeric nanoparticle with a particle diameter ranging from 60 to $150 \mathrm{~nm}$, delivering siRNA against the ribonucleotide reductase M2 subunit (RRM2) for the treatment of a variety of solid tumors (Zuckerman et al. 2014). RRM2 is essential for the regulation of nucleotide synthesis, and its expression is frequently upregulated in many cancers (Furuta et al. 2010). In a phase 1a clinical trial, 15 patients were treated with CALAA-01 delivering between 3 and $30 \mathrm{mg} / \mathrm{m}^{2}$ of siRNA (Zuckerman et al. 2014).
No initial dose-limiting toxicities were observed; however, approximately two years after initial treatment, two patients receiving the maximum dose experienced toxicity symptoms. The clinical protocol was subsequently modified to administer patients with a lower initial dose of CALAA-01, with the hypothesis that reduced initial exposure may dampen immunogenicity that was associated with toxicity (Zuckerman et al. 2014). However, the study was terminated when two out of five patients enrolled in the phase $1 \mathrm{~b}$ clinical trial developed doselimiting toxicities. The scientific report documenting the termination of the trial has not been published; however, preliminary results suggest that the toxicity of CALAA-01 is associated with the delivery vehicle rather than the siRNA (Zuckerman et al. 2014). It is proposed that these toxicities may be neutralized by alternative purification of CALAA-01 after its preparation (Zuckerman et al. 2014).

siG12D LODER is a biodegradable and implantable cylindrical rod (diameter: $0.9 \mathrm{~mm}$; length $4 \mathrm{~mm}$ ) that is composed of a copolymer of poly (lactic-co-glyolic) acid (PLGA) (Ramot et al. 2016). This polymer matrix encapsulates anti-KRAS $(12 G>D)$ siRNA (siG12D) to enable sustained local release of siG12D for the treatment of locally advanced pancreatic cancer (Zorde Khvalevsky et al. 2013, Golan et al. 2015, Ramot et al. 2016). Greater than $90 \%$ of pancreatic ductal adenocarcinomas (PDACs) harbor mutated KRAS, and the majority of these are activating mutations occurring within codon 12 . The most common codon 12-activating KRAS mutations include $12 \mathrm{G}>\mathrm{D}(61 \%), 12 \mathrm{G}>\mathrm{R}(18 \%)$ and $12 \mathrm{G}>\mathrm{V}(17 \%)$ (Rachakonda et al. 2013). Importantly, previous studies have demonstrated that PDAC cells are addicted to mutant KRAS, such that a reduction in KRAS expression is associated with reduced cell viability (Singh et al. 2009). These findings have set the foundation to silence mutant KRAS as a therapeutic strategy for PDAC treatment. The phase 1 clinical trial evaluating siG12D LODER consisted of 15 pancreatic cancer patients, divided into 3 dose cohorts. The siG12D LODER implant was inserted into the PDAC lesion via standard biopsy procedures for sustained release of siG12D for 4 months with concomitant weekly intravenous infusion of chemotherapy (Golan et al. 2015). Results indicate that the implant was safe and well tolerated, with transient adverse effects (Golan et al. 2015). Preliminary CT scans revealed that the majority of patients had stable disease, whereas 2 patients exhibited partial response (Golan et al. 2015). Moreover, 70\% of patients experienced a decrease in the pancreatic tumor marker, CA19-9 (Swords et al. 2016). A phase 2 clinical trial consisting of a larger cohort of patients to evaluate

Published by Bioscientifica Ltd 
the response rate of advanced pancreatic cancer patients treated with the chemotherapy and siG12D LODER is underway.

These clinical studies have laid a solid foundation of evaluating siRNA nanoparticles in various solid tumors, and additional trials are currently recruiting patients (Table 2). Lipid nanoparticles appear to be more widely tested than polymer nanoparticles in clinical trials; however, preliminary results from completed trials have demonstrated safety and efficacy using both nanomaterials. Successful evaluation of siRNA nanoparticles could potentially lead to the application of this powerful technology for the future treatment of various cancers, including breast cancer.

\section{Triple-negative breast cancer (TNBC) and current standard treatments}

Breast cancer is the most common cancer among women, with an estimated 246,660 newly diagnosed cases in the United States in 2016 (ACS 2016). Importantly, breast cancer is not a single disease; instead, it is clinically subcategorized into three major subtypes, which include hormone receptor-positive, HER2-positive and triplenegative breast cancers (TNBCs). This classification system has significant therapeutic and prognostic implications.

As its name suggests, TNBCs are those that lack estrogen receptor (ER) expression, progesterone receptor (PR) expression and HER2 amplification as determined by immunohistochemistry (IHC) and fluorescence in situ hybridization (FISH) analyses. There are currently no biomarkers that positively define TNBCs; therefore, TNBCs have been stratified by excluding tumors containing greater than $10 \%$ positivity in ER, PR and HER2. In 2010, the American Society of Clinical Oncology/College of American Pathologists (ASCO/CAP) updated their guidelines for defining ER- and PR-negative tumors as those having $<1 \%$ positivity to better accommodate patients who may benefit from endocrineand HER2-targeted therapies (Hammond et al. 2010). TNBCs are typically more clinically aggressive and occur more frequently in younger women and women of African and Hispanic ancestry (Alluri \& Newman 2014). Moreover, patients with TNBC are more likely to die from their disease within 5 years of diagnosis in comparison to patients with non-TNBC (Dent et al. 2007).

Unlike patients harboring luminal and HER2 breast cancers, who benefit from estrogen receptor and HER2 antagonists, there are no FDA-approved targeted therapies for the treatment of TNBC. Current standard local therapies include surgery and radiotherapy, whereas systemic therapy includes the use of cytotoxic chemotherapy (Yagata et al. 2011). TNBC lesions are typically unifocal, making breast conserving therapy a plausible option (Yagata et al. 2011). Regional and locoregional recurrences are typically higher in TNBC than those in non-TNBC; however, radiation therapy after surgery has been demonstrated to decrease recurrence (Kyndi et al. 2008, Voduc et al. 2010). Systemic therapy includes the use of taxane-anthracycline regimens that most TNBC patients initially respond to (Chacon \& Costanzo 2010, Stover \& Winer 2015); however, chemosensitivity is often shortlived and the majority of patients relapse and succumb to metastatic disease (O'Reilly et al. 2015). Additionally, in comparison to patients harboring non-TNBC, those harboring TNBC also typically experience shorter average time to local recurrence (2.8 years vs 4.2 years), shorter mean time to distant recurrence (2.6 years vs 5 years) and increased rate of distant recurrence (33.9\% vs $20.4 \%)$ (Dent et al. 2007). Because of these ongoing challenges associated with TNBC treatment, various novel targeted treatment approaches are currently being explored, including siRNA nanoparticles.

\section{Preclinical studies of siRNA nanoparticles in the treatment of TNBCs}

The clinical successes of siRNA nanoparticles for the treatment of various solid cancers have paved the way for its application in TNBC. Several recent preclinical studies have explored different siRNA delivery vehicles to silence an assortment of target genes that are associated with poor prognosis in TNBC. These studies have largely focused on siRNA nanoparticle application in 3 major areas for the treatment of TNBCs: inhibiting components of the cell cycle, inhibiting epithelial-mesenchymal transition (EMT) and improving chemotherapy efficacy.

\section{siRNA silencing of cell cycle regulators}

FOXM1 is a transcription factor that functions as a master regulator of the cell cycle by inducing $\mathrm{G} 1 \rightarrow \mathrm{S}$ and $\mathrm{G} 2 \rightarrow \mathrm{M}$ transitions (Saba et al. 2016). Notably, FOXM1 is overexpressed in many cancers, which has been correlated to metastasis and disease progression (Saba et al. 2016). In a recent study, Hamurcu and coworkers demonstrated that FOXM1 is overexpressed in numerous TNBC cell lines and that depletion of FOXM1 expression inhibits cyclin D1 expression and SRC (Y416) and ERK activation (Hamurcu et al. 2016). Functionally, these changes

Published by Bioscientifica Ltd 
coalesced to reduce colony formation, proliferation, invasion and migration (Hamurcu et al. 2016). Traditionally, transcription factors have commonly been thought of as 'undruggable' due to their lack of enzymatic activities (Yan \& Higgins 2013, Johnston \& Carroll 2015); however, these limitations are lifted by siRNA nanoparticles. Two weeks after nude mice were engrafted with MDA-MB-231 tumors, they were administered with control and FOXM1 targeting siRNA encapsulated within liposomal lipid nanoparticles at $0.3 \mathrm{mg} / \mathrm{kg}$ weekly (Hamurcu et al. 2016). Results demonstrated significant reduction of FOXM1 expression in the primary tumor, which was associated with decreased primary tumor burden (Fig. 3A) (Hamurcu et al. 2016). Future studies should evaluate tumor recurrence after withdrawal of FOXM1 siRNA nanoparticles.

In another study, cyclin-dependent kinase 11 (CDK11) and casein kinase II (CK2) were evaluated as potential therapeutic targets for the treatment of TNBCs (Kren et al. 2015). CDK11 and CK2 are two well-established molecular players that mediate cancer cell growth and survival. CDK11 is an atypical CDK that functions in mitosis, transcription and RNA splicing, and its elevated expression is observed in TNBCs (Zhou et al. 2016). CK2 is a Ser/Thr protein kinase that phosphorylates numerous substrates that function in cell biology processes such as transcription, cell cycle regulation, apoptosis and others (Meggio \& Pinna 2003). Elevated expression of CK2 in human breast cancers correlates with metastasis (Giusiano et al. 2011). Kren and coworkers encapsulated CDK11 and CK2 siRNAs into polyamine-based micelles that are coated with tenfibgen (TBG) protein. TBG is specifically recognized by tenascin $\mathrm{C}$, a receptor that is highly expressed in breast cancer stroma (Guttery et al. 2010). Control TBG-coated nanoparticles or those encapsulating siRNAs against CDK11 were administered via intravenous injection at a dose of $0.01 \mathrm{mg} / \mathrm{kg}$, every 3-4 days for 10 days. Mice receiving nanoparticles that delivered CDK11 siRNAs harbored significantly smaller primary tumors (Fig. 3A) (Kren et al. 2015). Future studies should evaluate the changes in metastatic potential of the xenografted tumors in response to nanoparticle administration.

In a third study, Liu and coworkers utilized siRNA nanoparticles to target CDK1, a cyclin-dependent kinase, that has recently been demonstrated to be synthetic lethal in TNBC models harboring elevated Myc expression (Horiuchi et al. 2012). MYC is an oncoprotein that is frequently overexpressed in TNBCs. Directly targeting MYC as a therapeutic strategy has not come to fruition
A siRNA nanoparticles targeting cell cycle

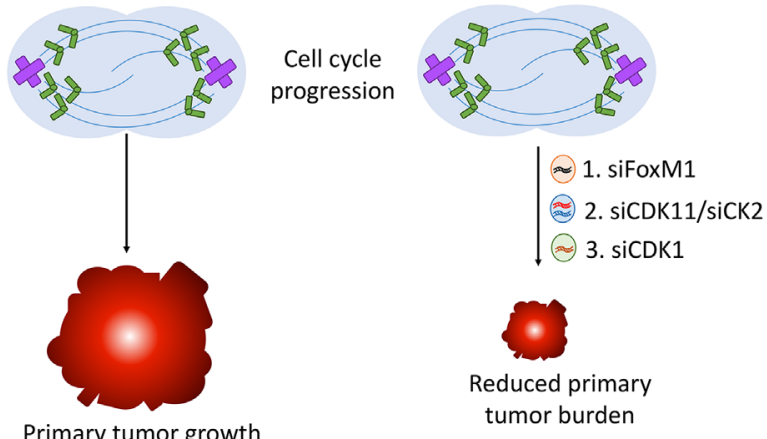

B

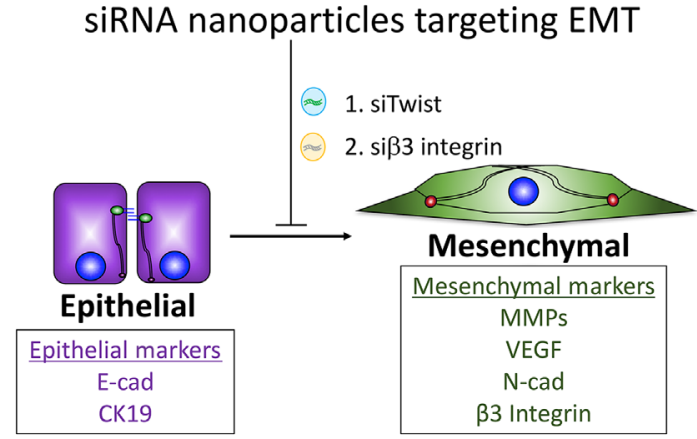

C siRNA nanoparticles improving chemotherapy

Nanoparticle cross sections

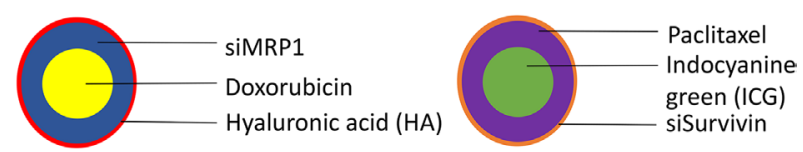

Figure 3

Current approaches using therapeutic siRNA nanoparticles in the treatment of TNBCs. (A) siRNA nanoparticles delivering siRNA against FoxM1, CDK11/CK2 and CDK1 are demonstrated to significantly reduce primary tumor burden. (B) siRNA nanoparticles silencing Twist and $\beta 3$ integrin inhibit EMT. Nanoparticles delivering $\beta 3$ integrin siRNA also reduce primary tumor burden, primary tumor recurrence and metastasis in MDA-MB-231 mouse xenograft models. (C) Complex nanoparticles utilize siRNAs to improve the chemotherapeutic efficacy.

because (1) designing a small-molecule inhibitor to disrupt protein-protein or protein-DNA interactions necessary for MYC function has proven to be challenging (Horiuchi et al. 2014) and (2) MYC expression is essential for regeneration and maintenance of stem cells in the bone marrow, skin and gastrointestinal tract (Soucek et al. 2008). Using a cationic lipid-based PEG-PLA nanoparticle system, Liu and coworkers delivered CDK1-specific siRNA to TNBC cells harboring elevated MYC expression and observed decreased Myc expression that is accompanied by (1) decreased cell viability, (2) decreased colony formation and (3) increased apoptosis in vitro (Liu et al. 2014). In vivo, administering siCDK1 nanoparticles culminated

Published by Bioscientifica Ltd 
in significant reduction of primary tumor burden (Fig. 3A). Importantly, no significant changes in body weight and inflammatory cytokines were noted, indicating no major toxicities (Liu et al. 2014). As with previous studies, changes in metastatic potential were not evaluated.

In summary, various groups have demonstrated the effectiveness of siRNA nanoparticles at reducing primary tumor burden by targeting key cell cycle regulators. Insignificant changes in body weight and immune cytokine production were observed, which suggest that these delivery platforms are safe and well tolerated. However, as most breast cancer patients undergo surgery to remove the primary tumor, and metastasis is ultimately the factor associated with patient mortality, future studies need to evaluate how tumor recurrence and metastatic potential can be targeted by these siRNA nanoparticles.

\section{siRNA silencing inducers of epithelial-mesenchymal transition}

Epithelial-mesenchymal transition (EMT) is a normal physiological program that occurs during development, fibrosis and wound healing (Taylor et al. 2010). Aberrant activation of EMT engenders its pathophysiological characteristics associated with cancer (Taylor et al. 2010). Over the past decade, the effects of EMT have been expanded to include alterations in cell motility and invasion, acquisition of stem-like characteristics, resistance to chemotherapy and remodeling of the tumor microenvironment (Morrison et al. 2013). Given its salient role in malignancy, attention has turned to targeting EMT for the treatment of TNBCs.

Various transcription factors, such as members of the TWIST, SNAIL and ZEB families, have previously been characterized as master regulators of EMT (Taylor et al. 2010). Recently, Finlay and coworkers utilized an amphiphilic dendrimer to silence TWIST1 in TNBC cells (Finlay et al. 2015). The authors verified target cell uptake of the dendriplexes that mediated significant reduction of TWIST1 expression in SUM1315 TNBC cells (Finlay et al. 2015). In vitro, the functional consequences of silencing TWIST1 coalesced to reduce (1) expression of the EMT markers, N-cadherin and vimentin and (2) cancer cell migration and invasion (Fig. 3B) (Finlay et al. 2015). Furthermore, the authors confirmed that intratumoral injection of the dendriplexes delivering a fluorescent siRNA effectively induced siRNA uptake by tumor cells and that the fluorescent siRNA was only minimally internalized by cells in other organs. Future studies will need to characterize the in vivo effects of dendriplexes delivering TWIST1 siRNA to TNBC xenograft models.

EMT can also be induced in response to microenvironmental regulators. $\beta 3$ integrin is a transmembrane protein that functions as the vitronectin and fibronectin receptor when it is homodimerized to $\alpha \mathrm{v}$ integrin (Parvani et al. 2013, Missirlis et al. 2016). Previous studies have demonstrated that $\beta 3$ integrin plays essential roles in transforming growth factor-beta (TGF- $\beta$ )-mediated EMT (Galliher \& Schiemann 2006, Parvani et al. 2013). Using a lipid-based siRNA carrier called ECO, Parvani and coworkers demonstrated that a single 4-hour dose of ECO/si $\beta 3$ lipid nanoparticles was sufficient to sustain prolonged silencing of $\beta 3$ integrin in both mouse and human breast cancer cell lines for up to 7 days (Parvani et al. 2015). Furthermore, silencing $\beta 3$ integrin in vitro inhibits EMT in TNBC cell lines, in part by the upregulation of epithelial markers, cytokeratin (CK) 19 and E-cadherin and downregulation of mesenchymal markers, $\mathrm{N}$-cadherin and PAI1 (Fig. 3B) (Parvani et al. 2015). $\beta 3$ integrin depletion also reduces proliferation and invasion in $2 \mathrm{D}$ cultures and inhibits 3D organotypic outgrowth. To improve the circulation time and tumor cell uptake, the $\mathrm{ECO} / \mathrm{si} \beta 3$ lipid nanoparticles were further modified with PEG, which is conjugated to an RGD peptide that is recognized by $\beta 3$ integrin (Iyer et al. 2013). When administered to nude mice engrafted with MDA-MB-231 tumors, RGD-ECO/si 33 lipid nanoparticles effectively decreased primary tumor burden, primary tumor recurrence and metastatic tumor burden (Parvani et al. 2015). The authors verified decreased $\beta 3$ integrin expression in primary tumors that were surgically removed, and H\&E staining of control and RGD-ECO/si 33 -treated tumors indicate reduced tumor-associated vasculature in the experimental group (Parvani et al. 2015).

In summary, these studies demonstrated that targeting EMT-inducing factors is an effective way to reduce tumorigenicity of TNBC. Because of the salient role EMT plays in mediating stem-like characteristics and drug resistance, future studies should explore how silencing EMT-inducing factors would affect these phenotypes. Future studies also need to determine which combination of EMT transcription factor, if silenced by siRNA nanoparticles, would be most efficacious at inhibiting TNBC disease progression.

\section{Improving chemotherapeutic efficacy}

In 1995, the FDA approved its first nanodrug, Doxil, a PEGylated liposomal formulation of doxorubicin

Published by Bioscientifica Ltd 
(Fajardo-Ortiz et al. 2014, Marchal et al. 2015). Liposomal encapsulation of doxorubicin prevents breakdown of the drug before reaching tumor cells. The effects of this are twofold: (1) increased cytotoxic effect of the drug is achieved as a greater amount of the drug is reaching tumor cells and (2) decreased side effects of the drug is also achieved as normal cells are exposed to the active drug less frequently (Lao et al. 2013). PEGylation of these liposomal formulations further extends circulation time that increases the propensity of the drug to reach tumor cells (Khan et al. 2015). These improvements have translated to clinical success, and Doxil is currently utilized to treat recurrent breast cancer. Despite these successes, limitations associated with Doxil remain. First, although the PEGylated formulation is associated with increased circulation time, the presence of the PEG moiety also creates steric hindrance that limits tumor cell uptake (Khan et al. 2015). Furthermore, doxorubicin inherently exhibits high affinity for extracellular matrix proteins, which further limits tumor cell uptake of the drug (Khan et al. 2015). These limitations are indicative that further modifications of Doxil are required for its optimal use. Deng and coworkers address these deficiencies by constructing a dual-siRNA-chemotherapy co-delivery system, where an siRNA film against multidrug-resistant protein 1 (MRP1) was built around a chemotherapy-loaded nanoparticle core (Fig. 3C). Furthermore, these nanoparticles were coated with hyaluronic acid (HA), which has previously been demonstrated to (1) enhance in vivo stability and (2) mediate active uptake by CD44, a receptor that is highly expressed on some TNBC cells (Deng et al. 2013). Nude mice engrafted with MDA-MB-468 tumors were treated with this elegant system every 5 days for 15 days, with each dose of the experimental group consisting of $1 \mathrm{mg} / \mathrm{kg}$ doxorubicin and $1 \mathrm{mg} / \mathrm{kg}$ MRP1 siRNA. The control group delivering MRP1 siRNA only did not exhibit tumor inhibitory effects. The experimental group delivering both the siRNA and doxorubicin reduced tumor volume by (1) 8-fold in comparison to vehicle-treated group and (2) by 4 -fold in comparison to the control group delivering doxorubicin only (Deng et al. 2013).

Another group combined photothermal therapy (PTT) with gene therapy and chemotherapy (Su et al. 2015). This 'triple punch' nanoparticle delivers paclitaxel, siRNA against survivin, a gene associated with poor prognosis in TNBCs and indocyanine green (ICG), a PTT agent that has been approved by the FDA as a clinical imaging agent (Fig. 3C) (Su et al. 2015). In response to near-infrared (NIR) laser irradiation, hyperthermia produced by ICG mediates deformation of the nanoparticle core structure, which induces the release of paclitaxel and survivin siRNA. MDA-MB-231 tumors were engrafted onto nude mice and treated with 2 doses of triple therapy nanoparticles (NP-IPS) that contain $0.32 \mu \mathrm{mol} / \mathrm{kg}$ of ICG, $0.54 \mu \mathrm{mol} / \mathrm{kg}$ of paclitaxel and $1.5 \mathrm{mg} / \mathrm{kg}$ of survivin siRNA within 30 days (Su et al. 2015). In comparison to control groups receiving mono or dual therapies, mice receiving NP-IPS had complete growth inhibition of MDA-MB-231 xenograft tumors, without any indication of tumor recurrence. Evaluation of post-mortem histopathology of various organ systems indicates no injury or damage in mice receiving nanoparticles.

\section{TNBC subtype-specific therapeutic strategies: what are the limitations and how do siRNA nanoparticles fit in?}

Previous studies have further subcategorized TNBCs into six distinct transcriptional subtypes (Lehmann et al. 2011). These include two basal-like (BL1 and BL2) subtypes, a mesenchymal (M) subtype, a luminal androgen receptor (LAR) subtype, a mesenchymal stem-like (MSL) subtype and an immunomodulatory (IM) subtype (Lehmann et al. 2011). Each of these subtypes preferentially respond to different therapeutic agents. Although current standard clinical practice for TNBC treatment do not take these 6 subtypes into account, efforts have been made in ongoing clinical trials to treat patients based on specific molecular subsets (Lehmann et al. 2015). In this section, we explore how siRNA nanoparticles can be utilized to enhance subtype-specific TNBC treatments.

\section{Basal-like TNBCs and cisplatin}

The BL1 and BL2 subtypes are enriched for cell cycle and DNA damage response genes and are preferentially sensitive to cisplatin (Lehmann et al. 2011). Cisplatin is a platinum-containing chemotherapy that exerts its therapeutic effects by binding to DNA, causing DNA cross-linking, which leads to apoptosis (Apps et al. 2015). Interestingly, BL breast cancers have striking similarities to BRCA1-mutated breast cancers, which exhibit defective DNA homologous recombination. Both BL breast cancers and BRCA1-mutated breast cancers are (1) diagnosed in younger women, have poor prognosis and high mitotic index; (2) characterized by genomic instability and (3) preferentially respond to DNA damaging agents as demonstrated in xenograft mouse models and in clinical trials (Lehmann et al. 2011, Toft \& Cryns 2011, Isakoff et al. 2015). Gene expression analysis indicates that

Published by Bioscientifica Ltd 
there is a subset of $\mathrm{BL}$ breast cancers that harbor $B R C A 1$ mutations, whereas other BL breast cancers retain wildtype (WT) BRCA1 (Prat et al. 2014). Those that retain WT $B R C A 1$ typically contain mutations or alterations in other molecular players of the homologous recombination pathway, which enhances chemosensitivity to platinum agents (Toft \& Cryns 2011, Prat et al. 2014, Baker et al. 2016). Although BL TNBCs are more responsive to cisplatin, resistance mechanisms have been documented. Mechanisms of cisplatin resistance include secondary reversion mutations in $B R C A 1 / 2$ that circumvent the therapeutic effects of cisplatin (Dhillon et al. 2011). Utilizing siRNA nanoparticles to eliminate BRCA1/2 expression in combination with cisplatin may eliminate these resistant mechanisms (Table 3). Should a reversion mutation in BRCA1/2 arise in a region that overlaps with the chosen $B R C A 1 / 2$ siRNA, alternative siRNA sequences against BRCA1/2 may be utilized. Because functional $B R C A 1$ is essential for DNA damage repair in normal cells, it is imperative that the siRNA delivery platform utilized to deliver BRCA1/2 siRNA exhibit tumor cell-specific uptake to reduce complications from off-target effects in other organ systems.

\section{Mesenchymal TNBCs and PI3K/mTOR inhibitors}

The mesenchymal subtype of TNBCs harbor elevated growth factor signaling and proteins involved in EMT and representative cell lines preferentially respond to PI3K/mTOR inhibitors (Lehmann et al. 2011). Clinical trials testing the combination of mTOR inhibitors with a variety of chemotherapies and EGFR-family-targeted agents are under way (Paplomata \& O'Regan 2014, Massihnia et al. 2016). Similarly, a phase 2 clinical trial evaluating the efficacy of BKM120, a pan class 1 PI3K inhibitor, is ongoing (Mohamed et al. 2013, Paplomata $\&$ O'Regan 2014). Within the past 2 decades, various modes of PI3K/mTOR and RAS/ERK signaling crosstalk have been elucidated (Mendoza et al. 2011), and efforts to utilize small molecule inhibitors against both pathways in combination are also being tested in phase 1 clinical trials (Jokinen \& Koivunen 2015). Preliminary studies have been disappointing, with a combined overall response rate of $4.7 \%$, suggesting that improved strategies to inhibiting these pathways are necessary (Jokinen \& Koivunen 2015).

Class 1 PI3K, consists of P110 $\alpha, P 110 \beta$ and P110 $\gamma$ catalytic kinases that exist as heterodimers. Previous studies utilizing several cancer cell lines have demonstrated that small molecule inhibitors against P110 $\beta$ were ineffective, whereas an siRNA approach that silences $P 110 \beta$ effectively inhibits proliferation (Weiss et al. 2007, Mendoza et al. 2011). Mechanistically, small molecule inhibition of $\mathrm{P} 110 \beta$ inhibits its kinase activity, which does not alter the expression levels of the PI3K regulatory subunit, P85. However, silencing P110 $\beta$ with siRNAs disables its scaffolding functions leading to decreased P85 expression. Alteration of the P85-to$P 110 \beta$ ratio induces negative feedback loops that coalesce to inhibit proliferation (Fan et al. 2006). These results suggest that siRNA nanoparticle silencing of catalytic PI3K kinases in combination with MEK inhibitors may be more effective than the utilization of small molecule inhibitors to both pathways (Table 3) (Jokinen \& Koivunen 2015). In addition to the advantages of silencing key players of the PI3K pathway, previous studies have also demonstrated that siRNAs can be adapted to specifically silence point mutations (Fleming et al. 2005). In fact, silencing mutant KRAS as a therapeutic strategy in the treatment of pancreatic cancer has been associated with clinical success (Table 2). As PIK3CA mutations are prevalent in TNBCs (Shah et al. 2012), preferential siRNA depletion of mutant gene expression is desirable, because this strategy is equipped to eliminate dose-limiting toxicities associated with PI3K inhibitors (Table 3). Collectively, these ideas suggest that an siRNA approach to silencing the PI3K pathway may be an effective therapeutic strategy in combination with chemotherapy because of its versatile effects in downregulating PI3K (1) kinase activity, (2) scaffolding activity and (3) mutations.

Table 3 siRNA nanoparticle strategies to augment proposed TNBC subtype-specific therapies.

\section{TNBC subtype}

Basal-like

Mesenchymal
Current proposed therapy

Cisplatin

$\mathrm{PI3K} / \mathrm{mTOR}$ inhibitor

\begin{tabular}{l} 
Proposed siRNA nanoparticle strategy \\
\hline SiBRCA+ cisplatin \\
sip110b+MEK inhibitor \\
siPIK3CA mutant + chemo \\
siGF combination \\
siEMT combination \\
Si $A R$
\end{tabular}

$A R$, androgen receptor; EMT, epithelial-mesenchymal transition; GF, growth factor. 
Alternatively, as TNBCs characterized by the $\mathrm{M}$ subtype also harbor elevated growth factor signaling, inhibition of growth factor pathways is also a viable therapeutic strategy. In fact, elevated EGFR expression is reported in up to $76 \%$ of TNBC patients (Martin et al. 2012), although inconsistent percentages are reported depending on the method of EGFR detection (Nakai et al. 2016). Current clinical trials have explored small molecule EGFR inhibitors and anti-EGFR monoclonal antibodies as single agents and in combination with chemotherapy (Nakai et al. 2016). Unfortunately, these trials have been disappointing, owing to the activation of alternative signaling pathways that mediate resistance (Nakai et al. 2016). siRNA nanoparticle silencing of a combination of growth factors may present as a feasible approach to circumvent current resistance mechanisms (Table 3), and future studies need to determine what combinations would be most efficacious. Similarly, as mesenchymal subtypes of TNBCs are also characterized with an increase in EMT gene signature, siRNA nanoparticle strategies to silence a combination of EMT transcription factors also presents as a feasible therapeutic strategy (Table 3).

In summary, utilization of siRNA nanoparticles as a therapeutic strategy to inhibit PI3K/mTOR, growth factor and EMT pathways represents an attractive solution to challenges that are associated with the use of available small molecule PI3K/mTOR inhibitors. Because functional inhibition of a target using small molecule inhibitors vs using siRNA strategies can have significantly different outcomes (Weiss et al. 2007), future studies need to clearly define what these differences are and which approach exerts the maximal therapeutic efficacy, while limiting toxicities. Future studies should also determine whether delivery of point-mutated siRNA can exert miRNA-like functions on the corresponding WT gene.

\section{Luminal androgen receptor expressing TNBCs and bicalutamide}

The LAR subtype exhibits elevated androgen receptor (AR) signaling and TNBC cell lines of this subtype preferentially responds to bicalutamide, an AR inhibitor. Approximately $10-43 \%$ of TNBCs express AR; however, the prognostic value of AR currently remains controversial (Pietri et al. 2016). Indeed, some studies have demonstrated that $A R$ expression is correlated to increased mortality (Hu et al. 2011), increased tumor stage and increased lymph node metastasis (McGhan et al. 2014), whereas others have shown that AR-expressing TNBCs have decreased lymph node metastasis (Rakha et al. 2007), decreased tumor burden (Luo et al. 2010, Park et al. 2011) and increased overall survival (Luo et al. 2010). The reasons behind these contradictory results are currently unclear, although it is possible that differences in scoring systems and utilized reagents could have contributed (McGhan et al. 2014). Recently, a phase 2 clinical trial with 26 patients harboring AR-positive and ER/PR-negative breast cancers demonstrated that approximately $19 \%$ of patients who received bicalutamide exhibited a 6-month clinical benefit (Gucalp et al. 2013). These results suggest that some patients clearly benefit from AR antagonists and further testing of next-generation AR-targeting agents, including enzalutamide and CYP17 inhibitors are under way (Gucalp et al. 2013). siRNA nanoparticles silencing AR have not been evaluated in the context of TNBCs. Lessons from treating prostate cancer patients with bicalutamide indicate that mutations in the hormone-binding pocket of AR can switch anti-androgen antagonists to gaining agonist functions, thereby driving drug resistance (Tian et al. 2015). It is tempting to speculate that siRNA silencing of AR could circumvent these limitations (Table 3). Future studies need to fully investigate which subsets of AR-expressing TNBC patients will benefit from AR-targeted therapies.

\section{TNBCs harboring stromal signatures}

Recently, the aforementioned six subtypes of TNBCs have been refined to four distinct transcriptional subtypes with differing clinical characteristics (Lehmann et al. 2016). These include the BL1, BL2, M and LAR subtypes, whereas the previously stratified MSL and IM subtypes are now descriptors that indicate the presence of stromal and immune cell within the primary tumor (Lehmann et al. 2016). Indeed, Lehmann and coworkers demonstrated that tumor subtypes changed to MSL when the matched stromal cells were included, suggesting that the MSL gene expression pattern is a characteristic of stromal cells (Lehmann et al. 2016). Prior to the refined 4 transcriptional subtype classification system, MSL TNBC cell lines exhibited in vitro sensitivity to dasatinib, a broadspectrum tyrosine kinase inhibitor that targets SRC family kinases (Lehmann et al. 2011). Not surprisingly, a phase 2 clinical trial evaluating dasatinib for the treatment of TNBC demonstrated only limited activity, and combinations with chemotherapies were subsequently explored (Finn et al. 2011). Dasatinib is synergistic when treated in combination with cetuximab and cisplatin in vitro (Kim et al. 2013). However, dasatinib treatment also exerts immunosuppressive effects (Blake et al. 2008,

Published by Bioscientifica Ltd 
Table 4 Proposed therapeutic strategies using siRNA nanoparticles to address stromal and immune cells within the primary tumor.

TNBC descriptor
Mesenchymal stem-like
Immunomodulatory

Proposed siRNA nanoparticle strategy

siRNA against stromal cells SiPD1/siPD-L1

Fraser et al. 2009), which may offset the effects of antitumor immunity. More recently, a nanoparticle formulation of dasatinib has been utilized in combination with the anti-microtubule chemotherapy, vincristine, and results indicate (1) enhanced tumor cell uptake of dasatinib, (2) increased apoptosis and (3) decreased vascular mimicry channels (Zeng et al. 2015). Whether or not nanoparticle delivery of anti-SRC siRNA can recapitulate the effects of liposomal dasatinib is unclear. However, the refinement of utilizing MSL as a description to highlight the presence of stromal cells in the microenvironment points at the possibility of utilizing siRNA nanoparticles to target not only tumor cells but also stromal cells that function in creating a supportive tumor microenvironment (Table 4). Future studies need to determine appropriate therapeutic targets for both the tumor epithelial and stromal components and localization strategies.

\section{TNBCs harboring immune infiltration}

Interestingly, approximately $20 \%$ of TNBCs are highly enriched for immune cell infiltration, which is (1) an indicator of good prognosis, (2) a predictor of improved relapse-free survival (Lehmann et al. 2016) and pathological complete response (pCR) and (3) suggestive that immunotherapy may be a good therapeutic option (Garcia-Teijido et al. 2016). Importantly, the anti-PD-1 immune checkpoint inhibiting monoclonal antibody, pembrolizumab, has recently demonstrated clinical activity in a phase $1 \mathrm{~b}$ clinical trial for the treatment of PD-L1-positive, heavily pretreated, metastatic TNBCs (Nanda et al. 2016). These preliminary studies demonstrate an overall response rate of $18.5 \%$, and a phase 2 clinical trial is underway. This overall response rate suggests that a subset of patients may be resistant to pembrolizumab and its incorporation for clinical use is currently unclear. Potential mechanisms of pembrolizumab resistance may involve (1) conformational changes or co-receptor expression that shields the therapeutic target from drug binding, (2) upregulation of alternative receptors that cooperate to induce hyperactivation of the therapeutic target, (3) activation of downstream effectors that bypass

the inhibitory effects of the drug and (4) mutation and constitutive activation of the therapeutic target. Whether or not pembrolizumab resistance actually involves these hypothetical resistance mechanisms is unclear. Interestingly, nanoparticle delivery of antiHER2 siRNA has been demonstrated to circumvent resistance mechanisms associated with trastuzumab, a humanized monoclonal antibody used for treating HER2 breast cancers ( $\mathrm{Gu}$ et al. 2016). It is tempting to speculate that silencing PD-1 or PD-L1 expression by siRNA nanoparticles may circumvent pembrolizumab resistance (Table 4); however, further testing, including initial studies to determine if siRNA nanoparticles can be adapted to specifically target PD-1 expression on lymphocytes are required.

\section{Ongoing challenges associated with the clinical use of siRNA nanoparticles}

Even though preclinical studies and recent clinical trials have established siRNA nanoparticles as a promising therapeutic strategy for cancer treatment, a number of ongoing challenges have limited the technology. First, the percentage of siRNA nanoparticles that are actually taken up by tumor cells is estimated to be only $0.7 \%$ of the injected dose (Wilhelm et al. 2016). Active targeting strategies such as those summarized in Table 1 improves nanoparticle uptake to $\sim 0.9 \%$; however, $0.9 \%$ of the injected dose still represents a miniscule amount. Although synthesizing sufficient nanoparticles for preclinical mouse models are not limited by these low uptake statistics (the average mouse is $20 \mathrm{~g}$ ), scaling these amounts up for applicability in humans may cause additional complications. Synthesis of nanoparticles in larger amounts may compromise function of the nanoparticles, for example, through aggregation (Wilhelm et al. 2016). The cost associated with the synthesis and quality control could be prohibitively high. Additionally, the large volume of nanoparticles administered into a patient could introduce additional technical challenges and issues with immunity. Lastly, because approximately $99 \%$ of the nanoparticles are not taken up by tumor cells, off-target effects may pose serious restrictions. However, the good news is that siRNA silencing of target genes by nanoparticles is a reversible process, and withdrawal of the nanoparticle should reverse potential side effects. Future studies need to clearly dissect the mechanisms of nanoparticle localization and uptake by tumor cells to exploit potential pathways that can improve tumor-specific accumulation.

Published by Bioscientifica Ltd. 


\section{Conclusion}

The success of using siRNA as a tool to dissect molecular pathways has prompted researchers to explore its potential as a therapeutic platform. Indeed, over the past decade, various siRNA nanoparticle strategies have been employed to treat solid tumors in clinical trials. Completed trials have demonstrated both lipid and polymer siRNA nanoparticles to be safe and effective for silencing target gene expression, and preliminary results indicate good therapeutic outcomes in a variety of cancers. These clinical studies have laid a solid foundation for the use of siRNA nanoparticles to address ongoing challenges in cancer treatment, such as the case for TNBC. There is currently a lack of effective FDA-approved targeted therapies for the treatment of TNBCs. Recent studies using high-throughput sequencing has revealed the diverse genetic heterogeneity of TNBC that may underlie the difficulty associated with designing an appropriate targeted therapy for the treatment of this disease. Various ongoing clinical trials are now evaluating TNBC treatment regimens based on distinct molecular characteristics, such as BRCA and LAR. Because TNBC is characterized by a heterogenous genetic landscape, the versatility of selectively targeting different genes by siRNA nanoparticles makes this technology an attractive therapeutic option for TNBC treatment. Various preclinical studies utilizing siRNA nanoparticles to target (1) components of the cell cycle, (2) factors that induce EMT and (3) factors that reduce chemotherapy efficacy have been demonstrated to inhibit TNBC disease progression in mouse models. siRNA nanoparticles may be further adapted to complement proposed therapeutic strategies associated with the recently identified TNBC subtypes. Many of these proposed strategies are currently being tested in clinical trials and the use of siRNA nanoparticles to complement them may further strengthen their therapeutic efficacy. Collectively, siRNA nanotechnology is a promising solution in eliminating the roadblocks to successful development of a targeted therapy for TNBC treatment.

\section{Declaration of interest}

The authors declare that there is no conflict of interest that could be perceived as prejudicing the impartiality of this review.

\section{Funding}

Research support was provided in part by the Department of Defense to JGP (BC133808) and by the National Institutes of Health to MWJ (R01 CA138421).

\section{Acknowledgements}

Members of the Jackson Laboratory are thanked for providing helpful comments and suggestions.

\section{References}

ACS 2016 Cancer Facts and Figures 2016. Atlanta, GA, USA: American Cancer Society (available at: https://www.cancer.org/content/dam/ cancer-org/research/cancer-facts-and-statistics/annual-cancer-factsand-figures/2016/cancer-facts-and-figures-2016.pdf).

Aleku M, Schulz P, Keil O, Santel A, Schaeper U, Dieckhoff B, Janke O, Endruschat J, Durieux B, Roder N, et al. 2008 Atu027, a liposomal small interfering RNA formulation targeting protein kinase N3, inhibits cancer progression. Cancer Research 68 9788-9798. (doi:10.1158/0008-5472.CAN-08-2428)

Alexis F, Pridgen E, Molnar LK \& Farokhzad OC 2008 Factors affecting the clearance and biodistribution of polymeric nanoparticles. Molecular Pharmaceutics 5 505-515. (doi:10.1021/mp800051m)

Alluri P \& Newman LA 2014 Basal-like and triple-negative breast cancers: searching for positives among many negatives. Surgical Oncology Clinics of North America 23 567-577. (doi:10.1016/j. soc.2014.03.003)

Apps MG, Choi EH \& Wheate NJ 2015 The state-of-play and future of platinum drugs. Endocrine-Related Cancer 22 R219-R233. (doi:10.1530/erc-15-0237)

Arosio D \& Casagrande C 2016 Advancement in integrin facilitated drug delivery. Advanced Drug Delivery Reviews 97 111-143. (doi:10.1016/j. addr.2015.12.001)

Azlan A, Dzaki N \& Azzam G 2016 Argonaute: the executor of small RNA function. Journal of Genetics and Genome 43 481-494. (doi:10.1016/j.jgg.2016.06.002)

Baker LA, Holliday H \& Swarbrick A 2016 ID4 controls luminal lineage commitment in normal mammary epithelium and inhibits BRCA1 function in basal-like breast cancer. Endocrine-Related Cancer 23 R381-R392. (doi:10.1530/ERC-16-0196)

Bakrania AK, Variya BC \& Patel SS 2016 Novel targets for paclitaxel nano formulations: hopes and hypes in triple negative breast cancer. Pharmacological Research 111 577-591. (doi:10.1016/j.phrs.2016.07.023)

Bargheer D, Giemsa A, Freund B, Heine M, Waurisch C, Stachowski GM, Hickey SG, Eychmuller A, Heeren J \& Nielsen P 2015 The distribution and degradation of radiolabeled superparamagnetic iron oxide nanoparticles and quantum dots in mice. Beilstein Journal of Nanotechnology 6 111-123. (doi:10.3762/bjnano.6.11)

Blake SJ, Bruce Lyons A, Fraser CK, Hayball JD \& Hughes TP 2008 Dasatinib suppresses in vitro natural killer cell cytotoxicity. Blood 111 4415-4416. (doi:10.1182/blood-2008-02-138701)

Cao N, Cheng D, Zou S, Ai H, Gao J \& Shuai X 2011 The synergistic effect of hierarchical assemblies of siRNA and chemotherapeutic drugs co-delivered into hepatic cancer cells. Biomaterials 32 2222-2232. (doi:10.1016/j.biomaterials.2010.11.061)

Chacon RD \& Costanzo MV 2010 Triple-negative breast cancer. Breast Cancer Research 12 (Supplement 2) S3. (doi:10.1186/bcr2574)

De Jong WH, Hagens WI, Krystek P, Burger MC, Sips AJ \& Geertsma RE 2008 Particle size-dependent organ distribution of gold nanoparticles after intravenous administration. Biomaterials 29 1912-1919. (doi:10.1016/j.biomaterials.2007.12.037)

Deen WM, Lazzara MJ \& Myers BD 2001 Structural determinants of glomerular permeability. American Journal of Physiology: Renal Physiology 281 F579-F596.

Deng ZJ, Morton SW, Ben-Akiva E, Dreaden EC, Shopsowitz KE \& Hammond PT 2013 Layer-by-layer nanoparticles for systemic codelivery of an anticancer drug and siRNA for potential triplenegative breast cancer treatment. ACS Nano 7 9571-9584. (doi:10.1021/nn4047925) 
Dent R, Trudeau M, Pritchard KI, Hanna WM, Kahn HK, Sawka CA, Lickley LA, Rawlinson E, Sun P \& Narod SA 2007 Triple-negative breast cancer: clinical features and patterns of recurrence. Clinical Cancer Research 13 4429-4434. (doi:10.1158/1078-0432.CCR-063045)

Dhillon KK, Swisher EM \& Taniguchi T 2011 Secondary mutations of BRCA1/2 and drug resistance. Cancer Science 102 663-669. (doi:10.1111/j.1349-7006.2010.01840.x)

Fajardo-Ortiz D, Duran L, Moreno L, Ochoa H \& Castano VM 2014 Mapping knowledge translation and innovation processes in Cancer Drug Development: the case of liposomal doxorubicin. Journal of Translational Medicine 12 227. (doi:10.1186/s12967-014-0227-9)

Fakhr E, Zare F \& Teimoori-Toolabi L 2016 Precise and efficient siRNA design: a key point in competent gene silencing. Cancer Gene Therapy 23 73-82. (doi:10.1038/cgt.2016.4)

Fan QW, Knight ZA, Goldenberg DD, Yu W, Mostov KE, Stokoe D, Shokat KM \& Weiss WA 2006 A dual PI3 kinase/mTOR inhibitor reveals emergent efficacy in glioma. Cancer Cells 9 341-349. (doi:10.1016/j.ccr.2006.03.029)

Feng Q, Yu MZ, Wang JC, Hou WJ, Gao LY, Ma XF, Pei XW, Niu YJ, Liu XY, Qiu C, et al. 2014 Synergistic inhibition of breast cancer by co-delivery of VEGF siRNA and paclitaxel via vapreotide-modified core-shell nanoparticles. Biomaterials 35 5028-5038. (doi:10.1016/j. biomaterials.2014.03.012)

Finlay J, Roberts CM, Lowe G, Loeza J, Rossi JJ \& Glackin CA 2015 RNA-based TWIST1 inhibition via dendrimer complex to reduce breast cancer cell metastasis. BioMed Research International 2015 382745. (doi:10.1155/2015/382745)

Finn RS, Bengala C, Ibrahim N, Roche H, Sparano J, Strauss LC, Fairchild J, Sy O \& Goldstein LJ 2011 Dasatinib as a single agent in triple-negative breast cancer: results of an open-label phase 2 study. Clinical Cancer Research 17 6905-6913. (doi:10.1158/1078-0432.CCR11-0288)

Fleming JB, Shen GL, Holloway SE, Davis M \& Brekken RA 2005 Molecular consequences of silencing mutant K-ras in pancreatic cancer cells: justification for K-ras-directed therapy. Molecular Cancer Research 3 413-423. (doi:10.1158/1541-7786.MCR-04-0206)

Fraser CK, Blake SJ, Diener KR, Lyons AB, Brown MP, Hughes TP \& Hayball JD 2009 Dasatinib inhibits recombinant viral antigenspecific murine CD4+ and CD8+ T-cell responses and NK-cell cytolytic activity in vitro and in vivo. Experimental Hematology $\mathbf{3 7}$ 256-265. (doi:10.1016/j.exphem.2008.09.013)

Furuta E, Okuda H, Kobayashi A \& Watabe K 2010 Metabolic genes in cancer: their roles in tumor progression and clinical implications. Biochimica et Biophysica Acta 1805 141-152. (doi:10.1016/j. bbcan.2010.01.005)

Galliher AJ \& Schiemann WP 2006 Beta3 integrin and Src facilitate transforming growth factor-beta mediated induction of epithelialmesenchymal transition in mammary epithelial cells. Breast Cancer Research 8 R42. (doi:10.1186/bcr1524)

Garcia-Teijido P, Cabal ML, Fernandez IP \& Perez YF 2016 Tumorinfiltrating lymphocytes in triple negative breast cancer: the future of immune targeting. Clinical Medicine Insights: Oncology 10 31-39. (doi:10.4137/CMO.S34540)

Geng Y, Dalhaimer P, Cai S, Tsai R, Tewari M, Minko T \& Discher DE 2007 Shape effects of filaments versus spherical particles in flow and drug delivery. Nature Nanotechnology 2 249-255. (doi:10.1038/nnano.2007.70)

Giusiano S, Cochet C, Filhol O, Duchemin-Pelletier E, Secq V, Bonnier P, Carcopino X, Boubli L, Birnbaum D, Garcia S, et al. 2011 Protein kinase CK2alpha subunit over-expression correlates with metastatic risk in breast carcinomas: quantitative immunohistochemistry in tissue microarrays. European Journal of Cancer 47 792-801. (doi:10.1016/j.ejca.2010.11.028)

Golan T, Khvalevsky EZ, Hubert A, Gabai RM, Hen N, Segal A, Domb A, Harari G, David EB, Raskin S, et al. 2015 RNAi therapy targeting KRAS in combination with chemotherapy for locally advanced pancreatic cancer patients. Oncotarget 6 24560-24570. (doi:10.18632/ oncotarget.4183)

Gopal S, Miller KB \& Jaffe IZ 2016 Molecular mechanisms for vascular complications of targeted cancer therapies. Clinical Science $\mathbf{1 3 0}$ 1763-1779. (doi:10.1042/CS20160246)

Gu S, Hu Z, Ngamcherdtrakul W, Castro DJ, Morry J, Reda MM, Gray JW \& Yantasee W 2016 Therapeutic siRNA for drug-resistant HER2positive breast cancer. Oncotarget 7 14727-14741. (doi:10.18632/ oncotarget.7409)

Guan R, Tapang P, Leverson JD, Albert D, Giranda VL \& Luo Y 2005 Small interfering RNA-mediated Polo-like kinase 1 depletion preferentially reduces the survival of p53-defective, oncogenic transformed cells and inhibits tumor growth in animals. Cancer Research 65 2698-2704. (doi:10.1158/0008-5472.CAN-04-2131)

Gucalp A, Tolaney S, Isakoff SJ, Ingle JN, Liu MC, Carey LA, Blackwell K, Rugo H, Nabell L, Forero A, et al. 2013 Phase II trial of bicalutamide in patients with androgen receptor-positive, estrogen receptornegative metastatic breast cancer. Clinical Cancer Research 19 5505-5512. (doi:10.1158/1078-0432.CCR-12-3327)

Guttery DS, Shaw JA, Lloyd K, Pringle JH \& Walker RA 2010 Expression of tenascin-C and its isoforms in the breast. Cancer Metastasis Reviews 29 595-606. (doi:10.1007/s10555-010-9249-9)

Hammond ME, Hayes DF, Dowsett M, Allred DC, Hagerty KL, Badve S, Fitzgibbons PL, Francis G, Goldstein NS, Hayes M, et al. 2010 American Society of Clinical Oncology/College Of American Pathologists guideline recommendations for immunohistochemical testing of estrogen and progesterone receptors in breast cancer. Journal of Clinical Oncology 28 2784-2795. (doi:10.1200/JCO.2009.25.6529)

Hamurcu Z, Ashour A, Kahraman N \& Ozpolat B 2016 FOXM1 regulates expression of eukaryotic elongation factor 2 kinase and promotes proliferation, invasion and tumorgenesis of human triple negative breast cancer cells. Oncotarget 7 16619-16635. (doi:10.18632/ oncotarget.7672)

Heine M, Bartelt A, Bruns OT, Bargheer D, Giemsa A, Freund B, Scheja L, Waurisch C, Eychmuller A, Reimer R, et al. 2014 The cell-type specific uptake of polymer-coated or micelle-embedded QDs and SPIOs does not provoke an acute pro-inflammatory response in the liver. Beilstein Journal of Nanotechnology 5 1432-1440. (doi:10.3762/ bjnano.5.155)

Hoelder S, Clarke PA \& Workman P 2012 Discovery of small molecule cancer drugs: successes, challenges and opportunities. Molecular Oncology 6 155-176. (doi:10.1016/j.molonc.2012.02.004)

Horiuchi D, Kusdra L, Huskey NE, Chandriani S, Lenburg ME, Gonzalez-Angulo AM, Creasman KJ, Bazarov AV, Smyth JW, Davis SE, et al. 2012 MYC pathway activation in triple-negative breast cancer is synthetic lethal with CDK inhibition. Journal of Experimental Medicine 209 679-696. (doi:10.1084/jem.20111512)

Horiuchi D, Anderton B \& Goga A 2014 Taking on challenging targets: making MYC druggable. American Society of Clinical Oncology Educational Book 34 e497-e502. (doi:10.14694/EdBook_AM.2014.34.e497)

Hu R, Dawood S, Holmes MD, Collins LC, Schnitt SJ, Cole K, Marotti JD, Hankinson SE, Colditz GA \& Tamimi RM 2011 Androgen receptor expression and breast cancer survival in postmenopausal women. Clinical Cancer Research 17 1867-1874. (doi:10.1158/1078-0432.CCR-10-2021)

Isakoff SJ, Mayer EL, He L, Traina TA, Carey LA, Krag KJ, Rugo HS, Liu MC, Stearns V, Come SE, et al. 2015 TBCRC009: a multicenter phase II clinical trial of platinum monotherapy with biomarker assessment in metastatic triple-negative breast cancer. Journal of Clinical Oncology 33 1902-1909. (doi:10.1200/JCO.2014.57.6660)

Iyer AK, Singh A, Ganta S \& Amiji MM 2013 Role of integrated cancer nanomedicine in overcoming drug resistance. Advanced Drug Delivery Reviews 65 1784-1802. (doi:10.1016/j.addr.2013.07.012)

Jeong JH, Park TG \& Kim SH 2011 Self-assembled and nanostructured siRNA delivery systems. Pharmaceutical Research 28 2072-2085. (doi:10.1007/s11095-011-0412-y) 
Johnston SJ \& Carroll JS 2015 Transcription factors and chromatin proteins as therapeutic targets in cancer. Biochimica et Biophysica Acta 1855 183-192. (doi:10.1016/j.bbcan.2015.02.002)

Jokerst JV, Lobovkina T, Zare RN \& Gambhir SS 2011 Nanoparticle PEGylation for imaging and therapy. Nanomedicine 6 715-728. (doi:10.2217/nnm.11.19)

Jokinen E \& Koivunen JP 2015 MEK and PI3K inhibition in solid tumors: rationale and evidence to date. Therapeutic Advances in Medical Oncology 7 170-180. (doi:10.1177/1758834015571111)

Khan DR, Webb MN, Cadotte TH \& Gavette MN 2015 Use of targeted liposome-based chemotherapeutics to treat breast cancer. Breast Cancer 9 1-5. (doi:10.4137/bcbcr.s29421)

Kim EM, Mueller K, Gartner E \& Boerner J 2013 Dasatinib is synergistic with cetuximab and cisplatin in triple-negative breast cancer cells. Journal of Surgical Research 185 231-239. (doi:10.1016/j.jss.2013.06.041)

Kobayashi H \& Tomari Y 2016 RISC assembly: coordination between small RNAs and argonaute proteins. Biochimica et Biophysica Acta 1859 71-81. (doi:10.1016/j.bbagrm.2015.08.007)

Kobayashi H, Sato N, Kawamoto S, Saga T, Hiraga A, Haque TL, Ishimori T, Konishi J, Togashi K \& Brechbiel MW 2001 Comparison of the macromolecular MR contrast agents with ethylenediaminecore versus ammonia-core generation- 6 polyamidoamine dendrimer. Bioconjugate Chemistry 12 100-107. (doi:10.1021/bc000075s)

Kren BT, Unger GM, Abedin MJ, Vogel RI, Henzler CM, Ahmed K \& Trembley JH 2015 Preclinical evaluation of cyclin dependent kinase 11 and casein kinase 2 survival kinases as RNA interference targets for triple negative breast cancer therapy. Breast Cancer Research $\mathbf{1 7}$ 19. (doi:10.1186/s13058-015-0524-0)

Kyndi M, Sorensen FB, Knudsen H, Overgaard M, Nielsen HM, Overgaard J \& Danish Breast Cancer Cooperative Group 2008 Estrogen receptor, progesterone receptor, HER-2, and response to postmastectomy radiotherapy in high-risk breast cancer: the Danish Breast Cancer Cooperative Group. Journal of Clinical Oncology 26 1419-1426. (doi:10.1200/JCO.2007.14.5565)

Lao J, Madani J, Puertolas T, Alvarez M, Hernandez A, Pazo-Cid R, Artal A \& Anton Torres A 2013 Liposomal doxorubicin in the treatment of breast cancer patients: a review. Journal of Drug Delivery 2013 456409. (doi:10.1155/2013/456409)

Lehmann BD, Bauer JA, Chen X, Sanders ME, Chakravarthy AB, Shyr Y \& Pietenpol JA 2011 Identification of human triple-negative breast cancer subtypes and preclinical models for selection of targeted therapies. Journal of Clinical Investigation 121 2750-2767. (doi:10.1172/JCI45014)

Lehmann BD, Pietenpol JA \& Tan AR 2015 Triple-negative breast cancer: molecular subtypes and new targets for therapy. American Society of Clinical Oncology Educational Book 35 e31-e39. (doi:10.14694/ EdBook_AM.2015.35.e31)

Lehmann BD, Jovanovic B, Chen X, Estrada MV, Johnson KN, Shyr Y, Moses HL, Sanders ME \& Pietenpol JA 2016 Refinement of triplenegative breast cancer molecular subtypes: implications for neoadjuvant chemotherapy selection. PLoS ONE 11 e0157368. (doi:10.1371/journal.pone.0157368)

Li W \& Szoka FC Jr 2007 Lipid-based nanoparticles for nucleic acid delivery. Pharmaceutical Research 24 438-449. (doi:10.1007/s11095006-9180-5)

Lim J, Guo Y, Rostollan CL, Stanfield J, Hsieh JT, Sun X \& Simanek EE 2008 The role of the size and number of polyethylene glycol chains in the biodistribution and tumor localization of triazine dendrimers. Molecular Pharmacology 5 540-547. (doi:10.1021/mp8000292)

Liu X 2015 Targeting polo-like kinases: a promising therapeutic approach for cancer treatment. Translational Oncology 8 185-195. (doi:10.1016/j.tranon.2015.03.010)

Liu Y, Zhu YH, Mao CQ, Dou S, Shen S, Tan ZB \& Wang J 2014 Triple negative breast cancer therapy with CDK1 siRNA delivered by cationic lipid assisted PEG-PLA nanoparticles. Journal of Controlled Release 192 114-121. (doi:10.1016/j.jconrel.2014.07.001)
Liu JY, Chiang T, Liu CH, Chern GG, Lin Ts T, Gao DY \& Chen Y 2015 Delivery of siRNA using CXCR4-targeted nanoparticles modulates tumor microenvironment and achieves a potent antitumor response in liver cancer. Molecular Therapy 23 1772-1782. (doi:10.1038/ $\mathrm{mt} .2015 .147)$

Longmire M, Choyke PL \& Kobayashi H 2008 Clearance properties of nano-sized particles and molecules as imaging agents: considerations and caveats. Nanomedicine 3 703-717. (doi:10.2217/17435889.3.5.703)

Longmire MR, Ogawa M, Choyke PL \& Kobayashi H 2011 Biologically optimized nanosized molecules and particles: more than just size. Bioconjugate Chemistry 22 993-1000. (doi:10.1021/bc200111p)

Lopez-Davila V, Seifalian AM \& Loizidou M 2012 Organic nanocarriers for cancer drug delivery. Current Opinion in Pharmacology 12 414-419. (doi:10.1016/j.coph.2012.02.011)

Lorenzer C, Dirin M, Winkler AM, Baumann V \& Winkler J 2015 Going beyond the liver: progress and challenges of targeted delivery of siRNA therapeutics. Journal of Controlled Release 203 1-15. (doi:10.1016/j.jconrel.2015.02.003)

Luo X, Shi YX, Li ZM \& Jiang WQ 2010 Expression and clinical significance of androgen receptor in triple negative breast cancer. Chinese Journal of Cancer 29 585-590. (doi:10.5732/ cjc.009.10673)

Malamas AS, Jin E, Gujrati M \& Lu ZR 2016 Dynamic contrast enhanced MRI assessing the antiangiogenic effect of silencing HIF-1alpha with targeted multifunctional ECO/siRNA nanoparticles. Molecular Pharmacology 13 2497-2506. (doi:10.1021/acs. molpharmaceut.6b00227)

Marchal S, El Hor A, Millard M, Gillon V \& Bezdetnaya L 2015 Anticancer drug delivery: an update on clinically applied nanotherapeutics. Drugs 75 1601-1611. (doi:10.1007/s40265-015-0453-3)

Martin V, Botta F, Zanellato E, Molinari F, Crippa S, Mazzucchelli L \& Frattini M 2012 Molecular characterization of EGFR and EGFRdownstream pathways in triple negative breast carcinomas with basal like features. Histology and Histopathology 27 785-792. (doi:10.1111/j.1365-2559.2011.04160.x)

Massihnia D, Galvano A, Fanale D, Perez A, Castiglia M, Incorvaia L, Listi A, Rizzo S, Cicero G, Bazan V, et al. 2016 Triple negative breast cancer: shedding light onto the role of pi3k/akt/mtor pathway. Oncotarget 7 60712-60722. (doi:10.18632/oncotarget.10858)

McGhan LJ, McCullough AE, Protheroe CA, Dueck AC, Lee JJ, Nunez-Nateras R, Castle EP, Gray RJ, Wasif N, Goetz MP, et al. 2014 Androgen receptor-positive triple negative breast cancer: a unique breast cancer subtype. Annals of Surgical Oncology 21 361-367. (doi:10.1245/s10434-013-3260-7)

Meggio F \& Pinna LA 2003 One-thousand-and-one substrates of protein kinase CK2? FASEB Journal 17 349-368. (doi:10.1096/fj.020473rev)

Mendoza MC, Er EE \& Blenis J 2011 The Ras-ERK and PI3K-mTOR pathways: cross-talk and compensation. Trends in Biochemical Sciences 36 320-328. (doi:10.1016/j.tibs.2011.03.006)

Miele E, Spinelli GP, Miele E, Di Fabrizio E, Ferretti E, Tomao S \& Gulino A 2012 Nanoparticle-based delivery of small interfering RNA: challenges for cancer therapy. International Journal of Nanomedicine $\mathbf{7}$ 3637-3657. (doi:10.2147/ijn.s23696)

Missirlis D, Haraszti T, Scheele C, Wiegand T, Diaz C, Neubauer S, Rechenmacher F, Kessler H \& Spatz JP 2016 Substrate engagement of integrins alpha5beta 1 and alphavbeta3 is necessary, but not sufficient, for high directional persistence in migration on fibronectin. Scientific Reports 6 23258. (doi:10.1038/srep23258)

Mohamed A, Krajewski K, Cakar B \& Ma CX 2013 Targeted therapy for breast cancer. American Journal of Pathology 183 1096-1112. (doi:10.1016/j.ajpath.2013.07.005)

Morrison CD, Parvani JG \& Schiemann WP 2013 The relevance of the TGF-beta Paradox to EMT-MET programs. Cancer Letters 341 30-40. (doi:10.1016/j.canlet.2013.02.048) 
Nahta R \& Esteva FJ 2006 HER2 therapy: molecular mechanisms of trastuzumab resistance. Breast Cancer Research 8 215. (doi:10.1186/ bcr1612)

Nakai K, Hung MC \& Yamaguchi H 2016 A perspective on anti-EGFR therapies targeting triple-negative breast cancer. American Journal of Cancer Research 6 1609-1623.

Nanda R, Chow LQ, Dees EC, Berger R, Gupta S, Geva R, Pusztai L, Pathiraja K, Aktan G, Cheng JD, et al. 2016 Pembrolizumab in patients with advanced triple-negative breast cancer: phase Ib KEYNOTE-012 study. Journal of Clinical Oncology 34 2460-2467. (doi:10.1200/JCO.2015.64.8931)

Naymagon L \& Abdul-Hay M 2016 Novel agents in the treatment of multiple myeloma: a review about the future. Journal of Hematology and Oncology 9 52. (doi:10.1186/s13045-016-0282-1)

Necela BM, Crozier JA, Andorfer CA, Lewis-Tuffin L, Kachergus JM, Geiger XJ, Kalari KR, Serie DJ, Sun Z, Moreno-Aspitia A, et al. 2015 Folate receptor-alpha (FOLR1) expression and function in triple negative tumors. PLOS ONE 10 e0122209. (doi:10.1371/journal. pone.0122209)

O'Reilly EA, Gubbins L, Sharma S, Tully R, Guang MH, Weiner-Gorzel K, McCaffrey J, Harrison M, Furlong F, Kell M, et al. 2015 The fate of chemoresistance in triple negative breast cancer (TNBC). BBA Clinical 3 257-275.

Ogawa M, Regino CA, Marcelino B, Williams M, Kosaka N, Bryant LH Jr, Choyke PL \& Kobayashi H 2010 New nanosized biocompatible MR contrast agents based on lysine-dendri-graft macromolecules. Bioconjugate Chemistry 21 955-960. (doi:10.1021/bc9005442)

Paplomata E \& O'Regan R 2014 The PI3K/AKT/mTOR pathway in breast cancer: targets, trials and biomarkers. Therapeutic Advances in Medical Oncology 6 154-166. (doi:10.1177/1758834014530023)

Park S, Koo JS, Kim MS, Park HS, Lee JS, Lee JS, Kim SI, Park BW \& Lee KS 2011 Androgen receptor expression is significantly associated with better outcomes in estrogen receptor-positive breast cancers. Annals of Oncology 22 1755-1762. (doi:10.1093/annonc/mdq678)

Parvani JG, Galliher-Beckley AJ, Schiemann BJ \& Schiemann WP 2013 Targeted inactivation of beta1 integrin induces beta3 integrin switching, which drives breast cancer metastasis by TGF-beta. Molecular Biology of the Cell 24 3449-3459. (doi:10.1091/mbc.E12-10-0776)

Parvani JG, Gujrati MD, Mack MA, Schiemann WP \& Lu ZR 2015 Silencing beta3 integrin by targeted ECO/siRNA nanoparticles inhibits EMT and metastasis of triple-negative breast cancer. Cancer Research 75 2316-2325. (doi:10.1158/0008-5472.CAN-14-3485)

Pietri E, Conteduca V, Andreis D, Massa I, Melegari E, Sarti S, Cecconetto L, Schirone A, Bravaccini S, Serra P, et al. 2016 Androgen receptor signaling pathways as a target for breast cancer treatment. Endocrine-Related Cancer 23 R485-R498. (doi:10.1530/ERC-16-0190)

Prat A, Cruz C, Hoadley KA, Diez O, Perou CM \& Balmana J 2014 Molecular features of the basal-like breast cancer subtype based on BRCA1 mutation status. Breast Cancer Research and Treatment 147 185-191. (doi:10.1007/s10549-014-3056-x)

Rachakonda PS, Bauer AS, Xie H, Campa D, Rizzato C, Canzian F, Beghelli S, Greenhalf W, Costello E, Schanne M, et al. 2013 Somatic mutations in exocrine pancreatic tumors: association with patient survival. PLOS ONE 8 e60870. (doi:10.1371/journal.pone.0060870)

Rakha EA, El-Sayed ME, Green AR, Lee AH, Robertson JF \& Ellis IO 2007 Prognostic markers in triple-negative breast cancer. Cancer 109 25-32. (doi:10.1002/cncr.22381)

Ramot Y, Rotkopf S, Gabai RM, Zorde Khvalevsky E, Muravnik S, Marzoli GA, Domb AJ, Shemi A \& Nyska A 2016 Preclinical safety evaluation in rats of a polymeric matrix containing an siRNA drug used as a local and prolonged delivery system for pancreatic cancer therapy. Toxicologic Pathology 44 856-865. (doi:10.1177/0192623316645860)

Saba R, Alsayed A, Zacny JP \& Dudek AZ 2016 The role of forkhead box protein M1 in breast cancer progression and resistance to therapy. International Journal of Breast Cancer 20169768183. (doi:10.1155/2016/9768183)
Sadekar S, Ray A, Janat-Amsbury M, Peterson CM \& Ghandehari H 2011 Comparative biodistribution of PAMAM dendrimers and HPMA copolymers in ovarian-tumor-bearing mice. Biomacromolecules 12 88-96. (doi:10.1021/bm101046d)

Santel A, Aleku M, Keil O, Endruschat J, Esche V, Fisch G, Dames S, Loffler K, Fechtner M, Arnold W, et al. 2006 A novel siRNA-lipoplex technology for RNA interference in the mouse vascular endothelium. Gene Therapy 13 1222-1234. (doi:10.1038/sj.gt.3302777)

Scholz C \& Wagner E 2012 Therapeutic plasmid DNA versus siRNA delivery: common and different tasks for synthetic carriers. Journal of Controlled Release 161 554-565. (doi:10.1016/j.jconrel.2011.11.014)

Schultheis B, Strumberg D, Santel A, Vank C, Gebhardt F, Keil O, Lange C, Giese K, Kaufmann J, Khan M, et al. 2014 First-in-human phase I study of the liposomal RNA interference therapeutic Atu027 in patients with advanced solid tumors. Journal of Clinical Oncology 32 4141-4148. (doi:10.1200/JCO.2013.55.0376)

Seitz S, Buchholz S, Schally AV, Jayakumar AR, Weber F, Papadia A, Rick FG, Szalontay L, Treszl A, Koster F, et al. 2013 Targeting triplenegative breast cancer through the somatostatin receptor with the new cytotoxic somatostatin analogue AN-162 (AEZS-124). Anticancer Drugs 24 150-157. (doi:10.1097/CAD.0b013e32835a7e29)

Shah SP, Roth A, Goya R, Oloumi A, Ha G, Zhao Y, Turashvili G, Ding J, Tse K, Haffari G, et al. 2012 The clonal and mutational evolution spectrum of primary triple-negative breast cancers. Nature $\mathbf{4 8 6}$ 395-399.

Singh A, Greninger P, Rhodes D, Koopman L, Violette S, Bardeesy N \& Settleman J 2009 A gene expression signature associated with 'K-Ras addiction' reveals regulators of EMT and tumor cell survival. Cancer Cell 15 489-500. (doi:10.1016/j.ccr.2009.03.022)

Soucek L, Whitfield J, Martins CP, Finch AJ, Murphy DJ, Sodir NM, Karnezis AN, Swigart LB, Nasi S \& Evan GI 2008 Modelling Myc inhibition as a cancer therapy. Nature 455 679-683. (doi:10.1038/ nature07260)

Spankuch B, Matthess Y, Knecht R, Zimmer B, Kaufmann M \& Strebhardt K 2004 Cancer inhibition in nude mice after systemic application of U6 promoter-driven short hairpin RNAs against PLK1. Journal of the National Cancer Institute 96 862-872. (doi:10.1093/jnci/djh146)

Stover DG \& Winer EP 2015 Tailoring adjuvant chemotherapy regimens for patients with triple negative breast cancer. Breast 24 (Supplement 2) S132-S135. (doi:10.1016/j.breast.2015.07.032)

Su S, Tian Y, Li Y, Ding Y, Ji T, Wu M, Wu Y \& Nie G 2015 'Triplepunch' strategy for triple negative breast cancer therapy with minimized drug dosage and improved antitumor efficacy. ACS Nano 9 1367-1378. (doi:10.1021/nn505729m)

Swords DS, Firpo MA, Scaife CL \& Mulvihill SJ 2016 Biomarkers in pancreatic adenocarcinoma: current perspectives. OncoTargets and Therapy 9 7459-7467. (doi:10.2147/OTT.S100510)

Tabernero J, Shapiro GI, LoRusso PM, Cervantes A, Schwartz GK, Weiss GJ, Paz-Ares L, Cho DC, Infante JR, Alsina M, et al. 2013 First-in-humans trial of an RNA interference therapeutic targeting VEGF and KSP in cancer patients with liver involvement. Cancer Discovery 3 406-417. (doi:10.1158/2159-8290.CD-12-0429)

Takai N, Hamanaka R, Yoshimatsu J \& Miyakawa I 2005 Polo-like kinases (Plks) and cancer. Oncogene 24 287-291. (doi:10.1038/sj. onc.1208272)

Taylor MA, Parvani JG \& Schiemann WP 2010 The pathophysiology of epithelial-mesenchymal transition induced by transforming growth factor-beta in normal and malignant mammary epithelial cells. Journal of Mammary Gland Biology and Neoplasia 15 169-190. (doi:10.1007/s10911-010-9181-1)

Tian X, He Y \& Zhou J 2015 Progress in antiandrogen design targeting hormone binding pocket to circumvent mutation based resistance. Frontiers in Pharmacology 6 57. (doi:10.3389/fphar.2015.00097)

Toft DJ \& Cryns VL 2011 Minireview: basal-like breast cancer: from molecular profiles to targeted therapies. Molecular Endocrinology 25 199-211. (doi:10.1210/me.2010-0164) 
Voduc KD, Cheang MC, Tyldesley S, Gelmon K, Nielsen TO \& Kennecke H 2010 Breast cancer subtypes and the risk of local and regional relapse. Journal of Clinical Oncology 28 1684-1691. (doi:10.1200/JCO.2009.24.9284)

Wang Y, Li Z, Han Y, Liang LH \& Ji A 2010 Nanoparticle-based delivery system for application of siRNA in vivo. Current Drug Metabolism 11 182-196. (doi:10.2174/138920010791110863)

Weiss WA, Taylor SS \& Shokat KM 2007 Recognizing and exploiting differences between RNAi and small-molecule inhibitors. Nature Chemical Biology 3 739-744. (doi:10.1038/ nchembio1207-739)

Wen AM \& Steinmetz NF 2016 Design of virus-based nanomaterials for medicine, biotechnology, and energy. Chemical Society Reviews $\mathbf{4 5}$ 4074-4126. (doi:10.1039/C5CS00287G)

Wilhelm S, Tavares AJ, Dai Q, Ohta S, Audet J, Dvorak HF \& Chan WCW 2016 Analysis of nanoparticle delivery to tumors. Nature Reviews Materials 1 16014. (doi:10.1038/ natrevmats.2016.14)

Xu H, Tian Y, Yuan X, Liu Y, Wu H, Liu Q, Wu GS \& Wu K 2016 Enrichment of CD44 in basal-type breast cancer correlates with EMT, cancer stem cell gene profile, and prognosis. OncoTargets and Therapy 9 431-444. (doi:10.2147/OTT.S97192)

Yagata H, Kajiura Y \& Yamauchi H 2011 Current strategy for triple-negative breast cancer: appropriate combination of surgery, radiation, and chemotherapy. Breast Cancer 18 165-173. (doi:10.1007/s12282-011-0254-9)

Yan C \& Higgins PJ 2013 Drugging the undruggable: transcription therapy for cancer. Biochimica et Biophysica Acta 1835 76-85. (doi:10.1016/j.bbcan.2012.11.002)

Young SW, Stenzel M \& Yang JL 2016 Nanoparticle-siRNA: a potential cancer therapy? Critical Reviews in Oncology/Hematology 98 159-169. (doi:10.1016/j.critrevonc.2015.10.015)
Zeng F, Ju RJ, Liu L, Xie HJ, Mu LM, Zhao Y, Yan Y, Hu YJ, Wu JS \& Lu WL 2015 Application of functional vincristine plus dasatinib liposomes to deletion of vasculogenic mimicry channels in triplenegative breast cancer. Oncotarget 6 36625-36642. (doi:10.18632/ oncotarget.5382)

Zhang X, Wang Q, Qin L, Fu H, Fang Y, Han B \& Duan Y 2016 EGFmodified mPEG-PLGA-PLL nanoparticle for delivering doxorubicin combined with Bcl-2 siRNA as a potential treatment strategy for lung cancer. Drug Delivery 23 2936-2945. (doi:10.3109/10717544.201 5.1126769)

Zhao X, Li F, Li Y, Wang H, Ren H, Chen J, Nie G \& Hao J 2015 Co-delivery of HIF1alpha siRNA and gemcitabine via biocompatible lipid-polymer hybrid nanoparticles for effective treatment of pancreatic cancer. Biomaterials 46 13-25. (doi:10.1016/j. biomaterials.2014.12.028)

Zhou Y, Shen JK, Hornicek FJ, Kan Q \& Duan Z 2016 The emerging roles and therapeutic potential of cyclin-dependent kinase 11 (CDK11) in human cancer. Oncotarget 7 40846-40859. (doi:10.18632/ oncotarget.8519)

Zintchenko A, Philipp A, Dehshahri A \& Wagner E 2008 Simple modifications of branched PEI lead to highly efficient siRNA carriers with low toxicity. Bioconjugate Chemistry 19 1448-1455. (doi:10.1021/bc800065f)

Zorde Khvalevsky E, Gabai R, Rachmut IH, Horwitz E, Brunschwig Z, Orbach A, Shemi A, Golan T, Domb AJ, Yavin E, et al. 2013 Mutant KRAS is a druggable target for pancreatic cancer. PNAS $\mathbf{1 1 0}$ 20723-20728. (doi:10.1073/pnas.1314307110)

Zuckerman JE, Gritli I, Tolcher A, Heidel JD, Lim D, Morgan R, Chmielowski B, Ribas A, Davis ME \& Yen Y 2014 Correlating animal and human phase Ia/Ib clinical data with CALAA-01, a targeted, polymer-based nanoparticle containing siRNA. PNAS 111 11449-11454. (doi:10.1073/pnas.1411393111)

Received in final form 23 January 2017

Accepted 1 February 2017

Accepted Preprint published online 1 February 2017
() 2017 Society for Endocrinology Printed in Great Britain
Published by Bioscientifica Ltd 